\title{
Los antecedentes históricos y comparativos del Código Civil Griego
}

\author{
por el Dr. PANAYOTIS J. ZEPOS *
}

El Código Civil vigente en Grecia desde 1946 tiene su propia "historia" que, en el caso particular, se remonta a muchas, muchas centurias en el pasado y deriva de fuentes que históricamente pertenecen a la remota era bizantina de la evolución del derecho. Sin embargo, como en el caso de otros Códigos, el Código Civil Griego se relaciona intimamente con las condiciones internacionales prevalecientes en la época contemporánea y es un reflejo del espiritu común de la Europa continental, difundido y presente a través de cada una de las legislaciones modernas de los pueblos europeos. Asimismo, como otros Códigos de Europa, el Código Civil griego combina diversos elementos históricos y comparativos. Más concretamente, el Código Civil griego de 1946 está compuesto de elementos greco-romanos y germánicos, según ellos se ofrecen ya sea en su revisión histórica o en la observación "empirica" de los sistemas juridicos comparados contemporáneos.

Cuando a principios del pasado sig'o, tras de muchos años de revolución contra el Imperio Otomano, el Helenismo una vez más fue libre e independiente para constituir el Estado Griego, los hombres que tenían la responsabilidad de la organización de esa Estado encararon de inmediato la cuestión de su legislación. En forma especifica, con respecto al Derecho Civil a aplicarse en el futuro, la cuestión de orientación era viva y urgente en vista del glorioso pasado histórico de Grecia y el esplendor de las entonces recientes y muy discutibles codificaciones europeas, o sea el Código Civil francés de 1804 y el Código Civil General austriaco de 1811.

Durante los largos años de la Revolución Griega contra los otomanos. aún cuando sus dirigentes estaban plenamente dedicados a la lucha, se las arreglaron a fin de encontrar el tiempo necesario para pensar también en la organización legislativa de su nación cuya libertad se alcanzó y fundó con su propio sudor y sangre. En esa forma, los dirigentes griegos mantuvieron estrechas relaciones con los filhelenos fuera de Grecia, quienes, por su parte, ayudaban a la nación no sólo con suministros y fondos, sinó también con ideas para su legislación futura. Desde este punto de vista la correspondencia cruzada entre el coronel británico Leicester Stanhope y Jeremias Bentham. 
filósofo inglés del derecho, es muy caracteristica y un tanto original. El coronel Stanhope vivió en Grecia durante la lucha de ésta por su libertad y mantuvo correspondencia con Bentham, cuyas ideas utilitarias eran grandemente apreciadas en el pais, aún cuando, como el mismo Stanhope escribia, el Código griego que estaba por elaborarse conforme a los "modelos benthamitas" y al principio "del mayor bien para el mayor número", debiera de hecho formularse conforme a la teoria del derecho bizantino "a fin de hacerlo aceptable para el pueblo"..

Se ha comprendido que la influencia de Bentham fue un simple episodio periódico, característico de la ansiedad sentida por los dirigentes en cuanto a la orientación al preparar la legislación. Debemos con seguridad aceptar el hecho de que esta ansiedad de lós hombres que comandaban la Revolución Griega era de lo más aguda e intensa durante ese periodo en vista de la necesidad de tener en cuenta la influencia histórica de la tradición bizantino-romana y el, prestigio de las últimas codificaciones europeas del derecho civil.

La importancia de la herencia histórica de la tradición bizantino-romana era considerablemente decisiva en ese momento especial de la historia. La lucha griega por la independencia era un movimiento hacia la liberación del pais del dominio del conquistador, que habia tomado posesión de Constantinopla en el infortunado dia 29 de mayo de 1453, y que asi había puesto fin al Imperio Bizantino Cristiano, Imperio de más de mil años de antigüedad.

El derecho de ese Imperio, o sea el derecho bizantino, habia permanecido vigente en Grecia aún después de la caída del Imperio Bizantino, como un derecho que, hasta que el conquistador lo tolerara, regulaba las relaciones entre los griegos y entre los cristianos en general. El "Hexabiblos" de $\mathrm{Ar}$ menopoulos del año 1345, habia constituido asi durante siglos la concisa colección bizantina que regulaba las re'aciones entre los griegos a través de todo el periodo de régimen turco. Además del Hexabiblos, hubo otras colecciones subsecuentes de derecho bizantino que se utilizaron durante los años de subyugación, y que confirman la opinión de que el derecho bizantino jamás cesó de ser válido en Grecia, así como en los Balcanes y Asia Menor; en otros términos, en todo lugar habitado por cristianos, giregos y otros pueblos.

Tal vez convenga mencionar aqui, porque es en principio importante, que cuando los Principados de Valaquia y Moldavia, que gozaron de un tratamiento especial y más favorable por parte del conquistador, cuando a fines del siglo XVIII y principios del XIX elaboraron ciertos códigos redactados en lengua griega, se basaron en principios de derecho bizantino.

El resultado fue que el antiguo Imperio Bizantino, aún después de su caida, representó en principio el eslabón que ligaba a los cristianos subyugados y concretamente a los griegos, con su remoto y glorioso pasado histórico. Por tanto, los griegos sublevados a principios del siglo anterior consideraban al derecho bizantino no sólo con la añoranza del pasado sinó también con la creencia de que eran sus herederos naturales y legales. 
Sin embargo, los legisladores griegos también fueron influidos por las grandes codificaciones de su época, o sea el Código Civil francés de 1804 y el Código Civil austriaco de 1811. Es un hecho que el Código Civil austriaco tuvo cierta atracción y fue utilizado como modelo principal del "Código Politico" de Scarlatos Kallimachis, redactado en griego en Jassy, Moldavia, en 1817. Pero fue principalmente el Código Civil francés el que ejerció influencia especial sobre los griegos a principios del siglo pasado no sólo por las ventajas generalmente admitidas que todos conocemos, sinó también debido a ciertas razones especiales para los griegos de la época por cuanto sentian hacia él una gran afinidad. Debemos en realidad mencionar aqui que los griegos ya estaban habituados al pensamiento jurídico francés a través de la aplicación del derecho mercantil francés de 1807 a sus relaciones comerciales y maritimas aún antes de la Revo'ución Griega de 1821. Esto ocurria en una época en que algunas traducciones griegas del código mercantil francés ya circulaban en Grecia. El Código de Comercio francés fue de hecho reconocido como código griego por todas las Asambleas Nacionales del periodo revolucionario, lo mismo que por el Presidente de la recién constituida nación griega, loannis Kapodistrias. Asi pues, en la práctica, los griegos estaban bien familiarizados con la mentalidad juridica francesa aún antes de su Revolución. pero ello no era sólo en esa forma, pues. podemos recordar que varios juristas griegos del periodo revolucionario y aun después de la Revolición, se educaron en Universidades francesas. Esos jóvenes intelectuales del derecho tuvieron la oportunidad de observar la simplicidad y claridad del Código Civil francés, experiencia que automáticamente los convirtió en sus de. fensores fervientes en Grecia. Por último, debe también subrayarse que esta inclinación a favor de dicho Código, en cierta forma fue reforzada por la circunstancia de que Francia muy recientemente habia pasado por las angustias de la Gran Revolución de 1789, y de que poseia principios liberales y democráticos que también habian constituido el fundamènto ideológico de la Revolución Griega de 1821. Como fácilmente puede verse, la tendencia griega de imitar la legislación francesa en el dominio del derecho civil era bastante y justificada.

Asi pues, cuando finalizó la Revolución Griega, los griegos encontrábanse bajo el hechizo de la herencia histórica del derecho bizantino que habia regido durante tantos siglos, pero, al mismo tiempo, tenían completa y clara conciencia de la significación del Código Civil francés. Frente a ese dilema. como resultado de una serie de proclamaciones hechas tanto durante el periodo revolucionario como después de éste, los legisladores griegos escogieron el derecho de sus "siempre memorables Emperadores Cristianos", o sea el derecho bizantino. Sin embargo, su adhesión al pasado histórico no impidió un empleo paralelo de legislaciones extranjeras contemporáneas, particu'armente la francesa, como resulta evidente de ciertas leyes especiales de ese periodo inicial, lo mismo que de las primeras obras sobre teoria juridica de dicho periodo. Este hecho justifica la observación de que, poco después de la Revolución y al principiar los años que a ella sigujeron, se aceptaba 
en forma general que el derecho del nuevo Estado Griego debia basarse históricamente en el derecho bizantino y comparativamente en el modelo del de. recho francés. Esta tendencia hacia la ampliación de las fronteras en el campo de la investigación comparativa se mantuvo en lo fundamental en Grecia a través de todo el siglo pasado y hasta 1946 cuando, después de tanítos años. la preparación y promulgación del Código Civil griego fueron finalmente logradas.

La lucha por la liberación de Grecia, que se había iniciado en 1821, terminó en 1830 con el reconocimiento del nuevo Estado Griego independiente. Un año más tarde, en 1831, el primer Presidente griego, loannis Kaposdistrias, fue asesinado, y después de dos años de anarquia el joven rey Otón llegó a Grecia en 1833. E'lo marcó el comienzo de un nuevo periodo, el periodo de la Regencia Bávara, que fue de grandes consecuencias en la evo. lución general de la legislación griega y sobre todo en el campo del derecho civil.

Pese a las circunstancias de que la Regencia Bávara pronto perdió favor en Grecia, emprendió empero la organización sistemática del nuevo Estado a través del sistema jurídico alemán. En esa forma, el pensamiento juridico alemán fue por primera vez introducido en Grecia sobre la ya existente influencia de la legislación francesa. Asi pues, èl campo de la legislación extranjera comparada, que pudiera servir finalmente como modelo a la legisla ción griega, fue ampliado en forma considerable.

A G. L. von Maurer, miembro de la Regencia Bávara, debe Grecia casi la total organización legislativa del país. Es a Matrer a quien debemos la redacción de la ley sobre la Organización de los Tribunales, del Código Penal y de los Códigos de Procedimientos Civiles y Penales. En su libro "Das Griechische Volk" publicado en Heidelberg en 1835, el mismo Maurer señaló que, al redactar esos cuatro Códigos, trató él de combinar la simplicidad francesa con la exactitud alemana. Cierto, en verdad, Maurer era alemán; pero estaba plenamente influido por las ideas liberales francesas con las que se habia familiarizado durante sus estudios jurídicos en París. El resultado de esta educación tranco-alemana de Maurer fue que sus códigos necesariamente llevaron la marca del método comparativo.

Maurer quiso expandir su actividad legislativa al derecho mercantil, y más tarde al civil. Con respecto al derecho civil tenía él ciertas dudas inspiradas por sus propias creencias teóricas. Maurer era un adepto de la Escuela Histórica de F. K. von Savigny y, por tanto, considerabä que el derecho, como producto del "Volksgeist", se manifestaba principalmente en las costumbres del pueblo. Habia diversas "costumbres" relacionadas. Por esta razón. Maurer preparó una colección de esas costumbres en vista a su fu- 
tura codificación. Esto, sin embargo, no pudo realizarlo porque fue llamađo a Baviera y tuvo que salir de Grecia en Julio de 1834 como resultado de intrigas de los miembros de la Regencia.

Después de que Maurer partió de Grecia en 1834, se publicó como Código de Comercio Griego una traducción del Código Civil francés. En cuanto al Código Civil, el Real Decreto de 23 de febrero de 1835 reiteró que "las leyes civiles de los Emperadores Bizantinos, comprendidas en el "hezabiblos" de Armanopoulos, serán aplicadas hasta la publicación del Código Civil que estaba por redactarse; sin embargo, las costumbres establecidas durante largos años de uso ininterrumpido y las decisiones de los tribunales serian vălidas dondequiera que prevalecieran". En esta forma, una nueva era se inició en la historia del derecho civil y en la redacción del Código Civil en Grecia, por virtud del Real Decreto y las actividades previas de Maurer.

Al interpretar el Real Decreto de 1835. los juristas griegos de la época aceptaron pronto la posición de que el derecho bizantino establecido como fuente del derecho significaba no sólo el derecho bizantino comprendido en el "hexabib'os" de Armenopoulos, sino también el contenido en todas las colecciones oficiales bizantinas publicadas por Justiniano hasta la caida del Imperio Bizantino. Esa interpretación esencialmente condujo al reconocimiento de que aún el derecho Justiniano era válido en Grecia, con la doble consecuencia ulterior de que dicha interpretación permitió la utilización en Grecia de la doctrina del Pandectino alemán y abrió el camino para que prevaleciera la forma del pensamiento jurídico alemán. Como resultado de la preponderancia de esta interpretación, el Pándectino y el "Professorenrecht" alemanes del siglo XIX fueron, en consecuencia, adoptados también en Grecia. La influencia de la teoria alemana fue paralela a la de la francesa, y esta última continuá existiendo en el país durante muchos años. Además, debido a la circunstancia de que después de 1837, cuando la Universidad de Atenas fue establecida, el derecho francés se enseñó en ella como asignatura inde. pendiente, la tendencia hacia-la observación comparativa fue subrayada más enfáticamente aún.

La consecuencia fue que en el sig'o XIX el derecho bizantino permane.ció básicamente siendo el derecho civil griego. Sin embargo, el estudio de éste fue emprendido conforme al método germánico que seguia el Pandectismo alemán, y su modernización en materias especiales, por ejemplo en el derecho de personas, de garantias reales, etc., fue estab'ecido legislativamente sobre la base del modelo francés. En esa forma, tuvimos en Grecia una combinación completa de los métodos histórico y comparativo, tanto en la teoría como en la práctica, combinación que es evidente también en la historia de los esfuerzos que, tras de largas y numerosas aventuras, condujo a la redacción del Código Civil que entró en vigencia en 1946.

Poco después de la promulgación del Real Decreto de 1835, se estableció una comisión para preparar el Código Civil. La comisión laboró du rante muchos años y redactó diversas leyes sobre materias especiales, pero no logró cumplir su misión principal de dotar al pais con un Código Civil 
único y completo. Una traducción griega del Código Civil francés apareció primeramente en 1836. Ciertas leyes (decretos legislativos) fueron redactadas siguiendo el modelo francés (por ejemplo, las relativas a personas, prenda, hipoteca, tutela y curatela) y puestas en vigor derogando las disposiciones bizantinas correlativas. Sin embargo, el proyecto de un Código Civil completo no apareció hasta 1874 . Este proyecto de Código subrayó el factor comparativo en cuanto a que, pese a que se elaboró principa'mente sobre la base del Código Civil francés, no obstante muestra algunas influencias de los Códigos italiano y sajón.

Más tarde, una nueva comisión establecida en 1911 redactó varias partes del Código Civil, fundamentalmente sobre la base del Código Civil alemán, pero también con influencias de los Códigos francés, italiano y suizo, lo mismo que del Proyecto húngaro de 1913. Empero, esa comisión fue asimismo disuelta en 1920, sin haber cumplido con su misión.

A juzgar por los resultados, una comisión establecida en 1830 fue más afortunada, ya que el Código Civil actualmente en vígor en Grecia es consecuencia de sus trabajos. Digo que esta comisión fue más afortunada, no sólo debido a que la opinión pública se hallaba para entonces enteramente "madura" y lista para aceptar la implantación de un nuevo Código, sino también debido a que los miembros integrantes de la comisión desempeñaron su labor de redactar el Código Civil conforme al mejor método posible, o sea no aceptando simplemente uno sólo de entre los modelos extranjeros, sino que su obra se realizó combinando los requisitos históricos previos que dictaron la conservación del derecho bizantino junto con las exigencias de la legislación moderna según se deducian éstas de un examen de todos los códigos europeos continentales ap'icables.

La Comisión de 1930 basó, su labor tanto en datos históricos como comparativos. Estos datos eran suministrados en gran medida por la realidad griega misma, ya que en 1930 Grecia tenía esencialmente más de un derecho, en la siguiente forma:

a) Básicamente el derecho bizantino-romano, según habia sido fijado de modo definitivo en el Real Decreto de 1835.

b) Diversas leyes especiales, algunas de las cuales habian sido redactadas sobre la base del derecho francés, (por ejemplo, la ley sobre personas, las disposiciones sobre tutela, curatela, prenda, hipoteca, etc.): y otras con base en el derecho alemán, por ejemplo, la ley sobre divorcios, sucesión testada e intestada, etc.): y, finalmente, otras basadas en el derecho suizo, por ejemplo, la ley sobre protección de hijos ilegitimos.

c) Finalmente, no debemos olvidar que habian subsistido en Grecia ciertos códigos locales, por ejemplo:

a) En Eptamisos, el Código Civil jonio de 1841, elaborado sobre la base del Código Civil francés, del Código del Reino de las Sicilias y de los "Statuta Veneta". 
b') En la isla de Samos, el Código Civil samio de 1899, elaborado con base en 'os Códigos Civiles francés, italiano y sajón.

c) En la isla de Creta, el Código Civil de 1903, que sólo conte. nía disposiciones sobre Principios Generales, el derecho de Contratos y Responsabilidad Civil y el derecho de Cosas, y que había sido principalmente elaborado sobre la base del Código Civil alemán de 1900.

No puede haber duda alguna que para un pais de las dimensiones de Grecia todas esas leyes eran excesivas. Sin embargo, esa multiplicidad legislativa indudablemente tuvo efectos favorables en razón de que los legisladores griegos $y$, en general, el pueblo griego, ya estaban familiarizados con los argumentos históricos y comparativos de su derecho. Esta familiaridad del pueblo con su derecho fue quizá un factor de importancia especial en el éxito logrado al elaborar el Código Civil que la Comisión de 1930 habia tratado de completar para 1940.

El año de 1940 fue el año en que se terminó el Código. Fue tambièn el año en que Grecia cayó en el torbellino de la Segunda Guerra Mundial. que determinó la suspensión de la vigencia del Código Civil. Más tarde, en 1945, otra Comisión revisó el Código con éxito, entregándolo completo y bien acabado como versión final de Código Civil del pais. Intervenciones de carácter politico, sin embargo, condujeron a la implantación del texto del Código Civil de 1940. A consecuencia de ello, el Código Civil vigente en toda Grecia como texto único y general desde 1946, es en realidad el Código redactado en 1940 y no el que fue revisado en 1945.

\section{III}

Conforme examinamos las caracteristicas principales del Código Civil Griego de 1946, debemos distinguir necesariamente su técnica de su esencia.

a) Con respeto a la "técnica" del Código Civil de Grecia, observamos la siguiente:

El Código Civil griego fue elaborado durante los años 1930-1940, durante un periodo en que, de los tres principales códigos europeos continentales, el Código Civil francés mantenía su esplendor, el Código Civil y el Código de las Obligaciones suizos se tenian en elevada estima por su atractivo y simplicidad, mientras que al mismo tiempo habia muchos partidarios y adeptos del Código Civil alemán. Los redactores griegos del Código Civil tuvieron a su disposición todos los "modelos" accesibles para preparar su propia codificación, pero la abundancia misma de modelos presentaba el dilema de cuál de ellos debian escoger; deberian preferir la concisión o la amplitud, la flexibilidad o la seguridad, el encanto o la profundidad? Al final. ellos escogieron una solución intermedia. Probablemente bajo la influencia 
de la idea aristotêlica de "moderación", los legisladores griegos prefirieron no omitir ninguna disposición necesaria, pero se negaron a descender a tediosos e injustificados detalles; prefirieron no sobrecargar su texto con dogmatismo, pero al mismo tiempo se aseguraron de que el mismo no estuviera desprovisto de la necesaria terminología técnica; prefirieron no redactar un código que fuera comprensib'e sólo para personas especializadas en el derecho, pero rehusaron sacrificar la exactitud juridica a la ingenua exigencia de los profanos de que todas las disposiciones se redactaran en forma de ser fácilmente comprendidas por todos a primera vista.

Asi pues, por lo que a la técnica se refiere, el Código Civil griego se encuentra entre el casuismo de los Códigos Civiles francés y alemán y la f'exibilidad del Código Civil y del Código de las Obligaciones suizos. La consecuencia de ellos ha sido que la zona que se dejó sin tocar y abierta al libre arbitrio juridico no es tan amplia como en el texto suizo ni tan estrecha como en el alemán. Ello puede tal vez explicar. aún si no lo justifica, el hecho de que en la revisión final del Código Civil griego no se incluyó ninguna disposición correspondiente al art. $1^{\circ}$ del Código Civil suizo, aunque la inclusión se habia propuesto repetidamente por el legislador que introdujo la Parte General del Código Civil.

Debe también observarse que, por cuanto a la técnica del Código Civil se refiere, al menos en principio y en términos generales, los legisladores evitaron hacer referencia de un artículo a otro. Por último, es digno de notarse que los 2035 artículos del Código Civil se han dividido en cinco partes, o sea los Principios Generales, el Derecho sobre Obligaciones y Responsabilidad Civil, los Derechos Reales, el Derecho de Familia y el Derecho Sucesorio. Esta división en cinco partes se debe obviamente a la influencia de la posición Pandectista que prevaleció en Grecia hasta la promulgación del Código Civil de 1946. y que fueron también claramente formuladas en el Código Civil alemán, prueba adicional de la combinación de los elementos históricos y comparativos que se encuentran en general en el Código Civil griego de 1946.

b) Además, cuando se examina la esencia de las disposiciones del Código Civil griego en contraste con su técnica, considero que debe reconocerse también que este Código es producto de la combinación de elementos históricos y comparativos. Esto aparece con claridad al revisar la consagración en el propio Código de aquel'os principios juridicos que en cualquier sistema legal se consideran constituir instituciones fundamentales en la formulación de cualquier Código Civil.

En el primer libro del Código Civil, o sea el de los Principios Generales, reglamenta las fuentes del derecho en general; el llamado Derecho Internacional Privado; la situación legal de las entidades físicas y juridicas; la interpretación y función de los actos jurídicos; el ejercicio de derechos; así como algunas de las disposiciones más importantes que a veces reflejan la evidente influencia de modelos históricos y en ocasiones comparativos. Asi, la sanción de la costumbre como fuente de derecho, con existencia paralela 
a la ley (artículo 19, con las modificaciones del artículo 2, pár. 2, del Decreto Legislativo 7/10. mayo, 1946), así como la claúsula general conforme a la cual la aplicación de las reglas de orden público no puede ser suspendida por voluntad de los particulares, representan disposiciones fuertemente influidas por la tradición histórica según fue establecida en el derecho romano y desarrollada en la teoria general del derecho hasta nuestra época. La misma fuerte tradición se encuentra también en muchas otras disposiciones, entre las cuales pueden particularmente observarse al l'egar a este punto, las relativas al reconocimiento de la doctrina de la voluntad según aparece en la reglamentación que hace el Código del "error" en lós actos jurídicos. Sin embargo, con respecto a esta última materia debe subrayarse el hecho de que el Código Civil griego autoriza considerables concesiones a favor de la doctrina de la voluntad declarada, por ejemplo en el artículo. 144 cuando dispone que el acto jurídico no es anulado por causa de error: $1^{\circ}$, si la otra parte contratante acepta la declaración de voluntad tal como la entendió el que sufrió el error; $2^{\circ}$, si la anulación es contraria a la buena fe. Esta última disposición en realidad reproduce y complementa la disposición del Código de las Obligaciones suizo, y es uno entre muchos preceptos que se encuentran bajo la influencia, ya del modelo histórico, o del puramente comparativo. Igualmente cierto, la base comparativa es evidente también en algunas otras disposiciones de los Principios Generales del Código Civil griego, entre las cuales deben cubrayarse las que se refieren a la protección de derechos sobre la personalidad (art. 57 y ss.), lo mismo que a la prohibición del abuso del derecho (artículo 281). Asi pues, la protección de derechos scbre la personalidad (artículo 57 y ss.) generalmente se reglamenta conforme al modelo de otros códigos extranjeros, en particular el Código Civil y el Código de las Obligaciones suizos. La influencia del Código Civil suizo es evidente también en la expresión de la prohibición del abuso del dercho en el artículo 281 del Código Civil griego que establece, en forma un tanto amplia, que "el ejercicio de un derecho está prohibido si excede manifiestamente los limites impuestos por la buena fe o las buenas costusibres o por el fin social o económico de aicho derecho". El predominio de modelos legislativos extranjeros es evidente en estas disposiciones, lo mismo que en muchas otras. Sin embargo, fuera de ellas, hay algunas otras disposiciones, en los Principios Generales que muestran la influencia compara. tiva, por ejemplo, las relativas al Derechs Internacional Privado (articulos 4-33). Por otra parte, ciertos preceptos ostentan la marca evidente nó sólo de modelos legislativos extranjeros sino también de teorias enseñadas en otros sitios. Por ejemplo, en el caso de la regulación de la responsabilidad que surge de negociaciones para celebrar un contrato, el Código Civil. bajo las influencias dominantes de las avanzadas teorias Pandectistas, disfone (artículo 197) que "En el curso de negociaciones para la conclusión de un contrato, las partes se deben mutuamente la conducta dictada por la buena fe y los usos en las relaciones de negocios", y en el artículo 198, que "El que ha causado, por su culpa, un perjuicio a la otra parte en el curso de ne- 
gociaciones para la conclusión de un contrato, debe repararlo aún si el contrato no ha sido concluido".

El Libro Segundo del Código Civil, que comprende el Derecho de Obligaciones y Responsabilidad Civil, está permeado por la teoría del Pandectismo según cobró su forma final en el Código alemán. Con la combinación de la tradición romana y el empleo principal del mode'o alemán, pero también de otros, tales como el francés y el suizo, es aparente en este libro que los legisladores griegos alcanzaron su fin de combinar los e'ementos históricos y comparativos.

Por supuesto, es completamente imposible pasar revista, aún superficial, a toda la materia. Sin embargo, trataré de ofrecer aquí algunos puntos de vista y observaciones generales, aunque limitándome a un bosquejo muy general.

Es digno de notarse que el Derecho de Obligaciones y Responsabilidad Civil del Código Civil griego está basado en el principio de la libertad de contratar, en el de mantenimiento de la buena fe y las buenas costumbres, $y$ en el de favorecer al deudor. De ellos, debemos observar que el principio de libertad de contratar está sujeto a diversas restricciones que usualmente se encuentran en todos los Códigos contemporáneos, y también a la restricción general del artículo 388 del Código Civil griego, que dispuso bajo la in fluencia de la "théorie de l'Imprévision" francesa y de la teoria del "Geschaftsgrudlage", que en caso de cambio imprevisto de las circunstancias bajo las cuales se celebró un contrato sinalagmático (debido a que por el contrato la obligación del deudor resulta desmesuradamente onerosa), el tribunal podrá, ya sea ajustar el contrato o decretar su extinción. Esta disposición es importante en principio y ha sido aplicada repetidamente en la jurisprudencia griega, y en esa forma ha sido adaptada a las enseñanzas de la teoria contemporánea al revisar el contrato según se encuentra en casi todas las legislaciones de la época. Por otra parte, en muchas disposiciones del Código Civil griego encontramos el principio de la buena fe y el de favorecer al deudor, que derivan de antiguas creencias, romanas y teutónicas, que fueron desarrolladas bajo la influencia humanistica.

Todos estos principios básicos han resultado en una ampliación del significado y esencia de la obligación en el derecho griego contemporáneo, en que la obligación es en realidad algo más que el simple "vinculum juris" romano, y consiste en un verdadero "organismo" en el sentido en que este concepto se enseña actualmente en la teoria general de las obligaciones.

Por lo demás, con respecto al Derecho de Obligaciones y Responsabilidad Civil, debe observarse que el Código Civil griego insistió en el reconocimiento de la llamada responsabilidad subjetiva (en otros términos, el Código Civil insistió en el principio de la responsabilidad basada en la culpa), con un reconocimiento paralelo de muchos casos de responsabilidad "objetiva", sin mediar culpa. La responsabilidad de restaurar aún el daño moral es asimismo reconocida, al menos tratándose de actos ilicitos, y en muchos casos el Código sanciona el reconocimiento de la obligación de pa- 
gar una indemnización razonab'e a juicio del jucz y, en ocasiones, el pago de indemnización que es proporcional al grado de la ofensa. Sobra el decirlo, todas estas disposiciones fueron el resultado de una revisión comparativa de los códigos civiles contemporáneos.

Debe además mencionarse la regulación de otros dos aspectos que, bajo todos los sistemas juridicos, se consideran fundamentales en la teoria del derecho de las obligaciones y responsabilidad civil, o sea la cuestión de incumplimiento de una obligación y la responsabilidad nacida de actos ilicitos.

Más concretamente, la cuestión del incumplimiento de una obligación constituye, como todos saben, un problema verdaderamente "crucial" en busca de una mejor solución legislativa. Asi, la so'ución dada en esta materia por el derecho romano era bastante vaga, mientras que, por otra parte, la teoria francesa del incumplimiento de la obligación, la llamada "inexécution du contrat", y la "Nichterful'ung" alemana, lo mismo que la "Breach of Contract" anglosajona, presentan tanto ventajas como desventajas. En vista de estos dudosos e hibridos elementos, el Código Civil griego se baró en el principio general correcto, o sea, que cualquier violación culpable de contrato, resulta en la responsabilidad del deudor.

Sin embargo, el Código Civil griego ha dividido este principio general en varias disposiciones que caen bajo las dos categorias fundamentales de "incumplimiento" de una obligación, o sea, a) la imposibilidad y b) la mora en la ejecución, aplicadas genera'mente a cualquier obligación, y en especial al contrato sinalagmático. En este punto, como en algunos otros, encontramos la combinación de la simplicidad francesa y anglosajona mezcladas con la exactitud y el casuísmo del Código Civil a'emán. Este fue de hecho un argumentu más bien importante en favor del mantenimiento de la división entre las dos categorias, división que quizá debió haberse abandonado (Código Civil griego, arts. 335 y ss. 362 y ss., 380 y ss., 383 yss.).

Al evaluar los preceptos sobre la responsabilidad nacida de actos ilicitos, puede fáci'mente percibirse la influencia del Pandectismo, lo mismo que la de los Códigos Civiles francés y alemán. En realidad, de conformidad con las enseñanzas evolucionadas de las teorias del Pandectismo que, al complementar las reglas de la lex Aqui'ia romana se habian acercado en esencia a la famosa disposición del artículo 1382 del Código Civil francés, el Código Civil griego incorporó en el artículo 914 la disposición general en el sentido de que "Aquel que, contrariamente a la ley, causa por su culpa un daño a otro, está obligado a la reparación".

Sin embargo, además de esta disposición general, siguiendo la teoría del Código Civil alemán, el Código griego adoptó determinadas disposiciones sobre responsabilidad en ciertas clases de actos ilicitos (por ejemplo. difanación, rumores, insultos al honor de la mujer, etc.), lo mismo que la disposición relativa a la ofensa contra las buenas costumbrẹs, esta última correspondiente al artícu'o 826 del Código Civil alemán. El Código Civil griego también adoptó disposiciones referentes a la responsabilidad por actos ilicitos realizados por otros, la responsabilidad del dueño de un animal, la 
responsabilidad por la caida de un edificio u otras obras, en las cuales estableció ya una responsabi'idad objetiva o subjetiva, siguiendo el modelo del Código Civil alemán. El Código Civil griego enfocó asi el problema de la responsabilidad resultante de actos ilícitos con el Pandectismo histórico. lo mismo que con datos comparativos.

Este espiritu se encuentra, en la tota'idad del Derecho de Obligaciones y Responsabilidad Civil, tanto en la llamada Parte General como en la Parte Especial que reglamenta los contratos particulares y otras relaciones y obligaciones especiales como el enriquecimiento injusto, la responsabilidad civil, etc. La contribución del factor histórico en el Derecho de Obligaciones y Responsabilidad Civil se realizó en la forma de las enseñanzas evolucionadas del Pandectismo que, como tales, constituyeron derecho válido en Grecia antes de la promulgación del Código Civil de 1946.

Aún aparte de ello, no obstante, la elaboración del Código Civil alemán, igual que la de otros Códigos como el francés, el suizo y otros, con frecuencia fue tomada en consideración. La deseada combinación de los datos históricos y comparativos da una caracteristica especial al Código Civil griego entre las demás codificaciones europeas contemporáneas.

c) Lo que sa ha dicho con respecto a los Principios Generales y al Derecho de Obligaciones y Responsabilidad Civil, puede reproducirse también en relación con los Derechos Reales, donde igualmente encontramos la combinación de elementos históricos y comparativos.

El Código Civil griego regu'a asi la posesión y la propiedad, lo mismo que las servidumbres, conforme al modele bizantino-romano. Hay ahí, sin embargo, diversas modificaciones y complementos basados en el modelo de legislaciones extranjeras contemporáneas, por ejemplo, el reconocimiento de la propiedad por pisos (Código Civil artícu'os 1002, 1117), conforme al modelo francés, la adquisición de la propiedad de muebles "bona fide" (Código Civil, articulo 1036), que sigue el modelo alemán, etc. Sin embargo, las disposiciones sobre inscripción de inmuebles (Código Civil, artícu'os 1192 y ss.), sobre prenda (articulos 1209 y ss.), y sobre hipotecas (articulos 1257 y ss.) han sido elaborados según el modelo francés, materias sobre las cuales se habian redactado leves especiales a principios del pasado siglo y que habian formado parte del derecho vigente en Grecia hasta el año 1946 en que se promulgó el Código actual.

d) El Derecho de Familia naturalmente se refiere al derecho tradicio. nal en Grecia según se estableció históricamente durante muchos siglos bajo la influencia del derecho bizantino y los conceptos de la iglesia ortodoxa oriental. Ello se aplica en particular con referencia al matrimonio, que necesar'amente debe ser religioso, esto es, celebrado por un sacerdote ortodoxo a fin de ser válido. El matrimonio fue así impuesto también en el Código Civil griego, no por un espiritu teocrático sino en el de respeto histórico, reconociendo que desde el siglo VIII se había aplicado en Bizancio en forma ininterrumpida. Otras disposiciones determinadas tienen también un origen histórico, por ejemplo, las relativas a los impedimentos del matrimonio, la 
regulación de las relaciones patrimoniales entre marido y mujer, el sistema de bienes independientes (separación de bienes), etc.

Estas disposicions, como es natural, han sufrido modificaciones y complementos especiales; sin embargo, básicamente el derecho bizantino prevalece en ellas. Por el contrario, otras materias del Derecho de Familia han sido reglamentadas, aún antes del Código Civil, por leyes especiales fundadas en modelos legislativos bastante recientes, por ejemplo, las leves sobre divorcio, que siguen principalmente el modelo alemán; las disposiciones sobre el reconocimiento de hijos ilegítimos, que siguen el modelo suizo, los preceptos sobre curatela y tutela, que siguen el modelo francés.

e) Por último, debemos considerar la Ley sobre Herencias que también en diversos aspectos había sido formulada con anterioridad a la promulgación del Código Civil, a través de leyes especiales modernas, y que también presenta la característica de reflejar en forma básica el derecho bizantino, pero con modificaciones y complementos esenciales conforme al modelo de las nuevas legislaciones extranjeras, sobre todo el Código Civil alemán. Asi, en las disposiciones relativas a la sucesión por testamento e intestada, la institución del certificado de herencia y algunas otras han seguido en su elaboración el modelo alemán. Por lo demás, empero, el derecho bizantino continúa preponderando también sobre este sector del Código Civil, que in. cluye la Ley sobre Herencias.

\section{IV}

Con estos comentarios llego al final de esta breve revista del contenido de los fundamentos históricos y comparativos del Código Civil griego.

Permitidme, al llegar a este punto, reproducir aqui lo que dije hace unos quince años en las conferencias que ofreci en la Universidad de Cambridge. Inglaterra, resumiendo mis conclusiones acerca de las principales características del Código Civil griego.

He tratado de mostrar como este Código, tras de largos intentos, al fin ha podido liberarse de cualquier influencia exclusiva derivada de sistemas jurídicos extranjeros, y como, básicamente, reproduciendo la tradición romano-bizantina, que representa una tradición juridica griega, ha sido elaborado mediante el empleo del método comparativo.

El derecho comparado, o, mejor dicho, el método comparativo ha constituido una antigua tradición en la ciencia juridica griega. Desde los tiempos de Platón. Aristóteles y Teofrasto, cuyas investigaciones comparativas en las leyes de la comunidad griega nos ofrecen la primera crónica del método comparativo en la historia del derecho, hasta épocas más recientes, cuando el derecho extranjero en Grecia durante el pasado siglo, ya en forma de legislación o de jurisprudencia, fue estudiado con tanto éxito. el método comparativo ha florecido en el pais. 
El nuevo Código de Grecia es producto de esa investigación comparativa por parte de los juristas griegos. Este Código no representa una codificación revolucionaria; es más bien la elaboración cristalizada del pensamiento jurídico actual y del derecho griego que ya estaba en vigencia. Aqui tal vez exista una posible debilidad, ya que los Códigos y codificaciones tienen como misión, siempre que ello sea factible, disponer para las necesidades de la vida jurídica no sólo para el momento presente, sino para el futuro. Este Código sin embargo, reproduce el "status quo" del pensamiento jurídico actual, pero me aventuro a afirmar que este pensamiento juridico habia alcanzado una etapa de desarrollo y madurez que permitió tal codificación.

El nuevo Código no contiene disposición alguna como el famoso articulo $1^{\circ}$ del Código Civil suizo o el artículo 21 del Código Civil de Luisiana. Después de debatir, los redactores del Código prefirieron dejar todo el problema de llenar las llamadas lagunas de la ley a los juristas y a los tribunales. Si, empero, e! Código no sigue la moderna tendencia a este respecto, puede decirse que la adopción de disposiciones generales, según aparecen en expresiones tales como "buenas costumbres", "justicia y equidad", "orden público", "abuso de derechos", "buena fe", "uso de negocios", representa un logro que está en plena conformidad con los requisitos de la teoria juridica y práctica moderna en Europa. Estos principios presuponen una ac. tividad generosa y sabia por parte de los tribunales. Me atrevo a afirmar que la justicia griega, en conjunto, siempre ha dado pruebas de un cuidadoso y sabio desarrollo del derecho, que puede también esperarse confiadamente en la aplicación del nuevo Código Civil en el futuro.

\section{NOTA BIOGRAFICA DEL AUTOR}

El Decano Panayotis ZEPOS, Profesor Universitario, autor de este articulo, nació en Atenas en 1908. Hizo sus estudios de Derecho en las Universidades de Atenas y Berlin y estudios de Ciencias Económicas en la Universidad de Atenas. Profesor Asistente de Derecho Civil en la Universidad de Atenas (1939). Profesor de Derecho Civil en la Universidad de Salónica (1940). Profesor Titular de Derecho Civil en la Universidad de Atenas (1953. Secretario General del Ministerio de Justicia (1935) y del Ministerio de Educación (1945). Presidente de la Comisión encargada de elaborar un Código Civil Aéreo (1955). Secretario General del Congreso Bizantino (1953). Invitado por las Universidades Britanicas de Oxford y Cambridge para dictar una serie de Conferencias, en 1945-1946. Ha dictado Conferenciac en las Universidades de Paris, Marburg, Francfort, Zurich, Berna, Basilea y Estrasburgo. Doctor Honoris Causa de la Universidad de Friburgo. Miembro del Conseáo Directivo del Instituto Internacional para la Unificación del Derecho Privado (Roma). Director del Instituto Helénice de Derecho Internacional (Atenas). Director de Jas publicaciones juridicas: "Archivos de Derecho Privado" y "Diario de Juristas Griegos". Miembro del Comité Editorial de las revistas juridicas extranjeras: "Tulane Law Review" y "Revista di Diritto del Lavoro", de la revista histórica "Peloponnisiska". Autor de las siguientes obras: "Ownership according to storeys", (1935), "Jus Graecoromanum" (8 volúmenes, en calaboración con J. Zepos). "Doppelwirkungen in Civil Law (1934). 
"Moxern Greek Law and Lega! Science of the Hellens" (1934), "Legal Code of Alexandras Yysidantis, 1780" (1936), "Responsability from torts of third partici" (1937). "Greek I aw" (1949), "Law of Obligations" (2 vols.), "The Modern Greek Science of Civil Law" (1953), "Acts of the 1953 Byzantine Cungress" (3 vols en colaboracion con St. Kyriakidis y A. Xyngopoulos - 1955/58), "Morikon Procheiron de M. Pthoteinopoulos" (1959), asis como numerosos articulos y estudios publicados en revistas griegas y de otros paises.

De la Redacción: Agradecemos, de manera muy especial al Decano, Doctor Panayotis Zepos quien ha tenidu la gentileza de autorizarnos a publicar en nuestra revista su interesante estudio sobre el Código Civil Gricgc. También va inuestra gratitud al Doctor Rodolfo Batiza, Director del "Inter-American Law Review", de la Universidad de Tulane, mediante cuya amabla gestión obtutivos tal autorización, ya que el citado estudio fue orit ginalmente publicado en su notable Revista editada en inglés y en castellano. (Vol. III 1961, No 2, págs. 284/316). J. K. M. 